\title{
Clinical and Functional Outcomes in Patients with Distal Tibial Fracture Treated by Circular External Fixation: A Retrospective Cohort Study
}

\author{
Vasileios P Giannoudis ${ }^{1}$, Emma Ewins ${ }^{2}$, D Martin Taylor ${ }^{3}$, Patrick Foster ${ }^{4}$, Paul Harwood ${ }^{5}$
}

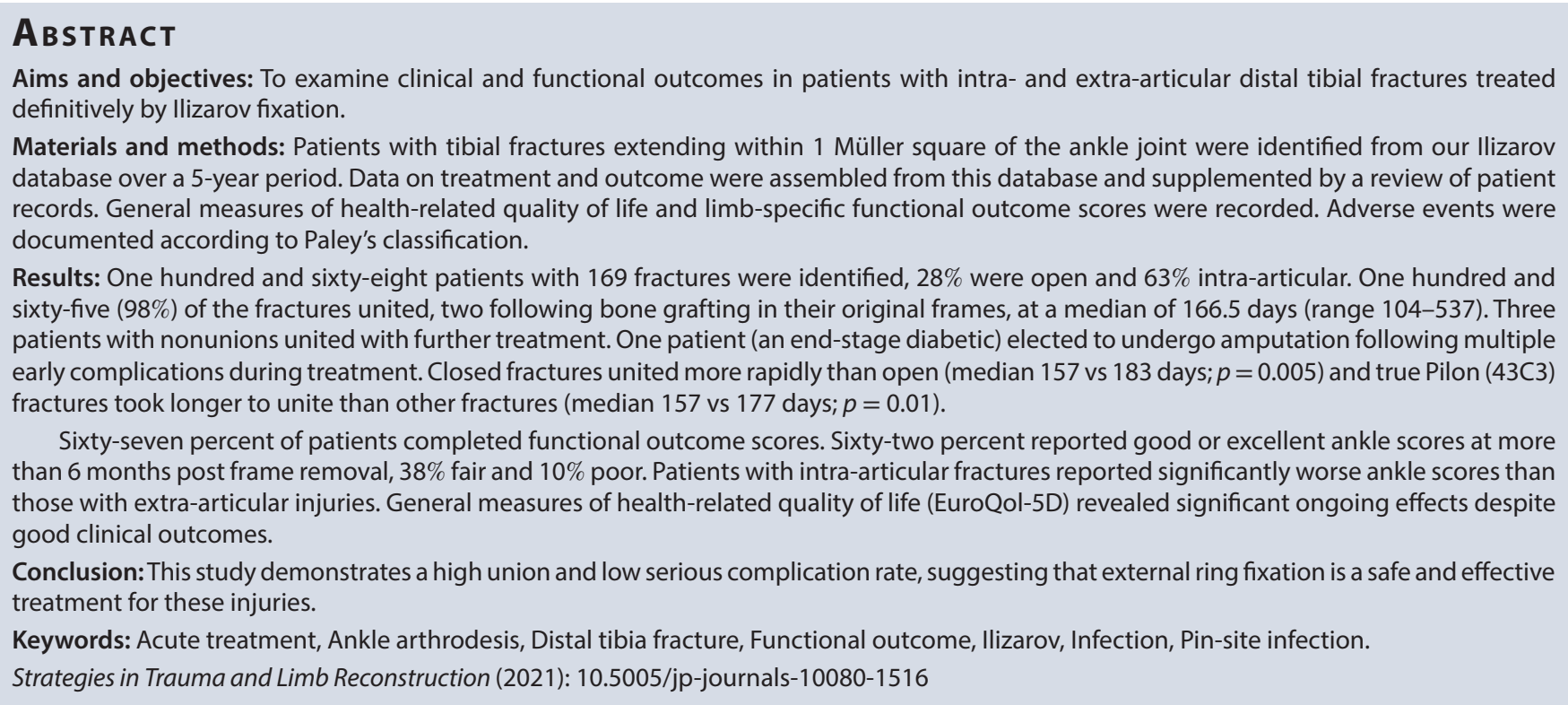

\section{INTRODUCTION}

Distal tibia fractures are often caused by high-energy trauma and are associated with soft tissue injury. Having high complication rates, various approaches to treatment have been suggested. ${ }^{1-3}$ To minimise further soft tissue damage and reduce implant footprint, some surgeons advocate treatment by definitive external fixation. ${ }^{4,5}$ The lack of evidence regarding the risks and advantages of different treatments and their outcomes has been highlighted. ${ }^{6}$ Though a large randomised control trial UK fixation of distal tibial fractures trial (FixDT) has recently been published, this does not include an external fixation arm nor patients with intra-articular injuries. ${ }^{7}$

Following the introduction of Major Trauma Networks in the United Kingdom and guidance advising treatment of complex fractures in specialist centers, increased numbers of patients with distal tibial fractures have presented to our department. ${ }^{8,9} \mathrm{~A}$ significant number are managed by definitive external fixation, we, therefore examined outcomes in this group.

The aim of this study was to assess clinical and functional outcomes in our patients with distal tibial fractures treated by external ring (llizarov) fixation. A retrospective cohort study was undertaken for this purpose. The primary outcome measure was the rate of bony union. Secondary outcomes were time to union, complication rates, and patient-reported outcome measures.

\footnotetext{
${ }^{1-2}$ School of Medicine, University of Leeds, Leeds, United Kingdom

${ }^{3-5}$ Department of Trauma and Orthopaedics, Leeds Teaching Hospitals, Leeds, United Kingdom
}

Corresponding Author: Paul Harwood, Department of Trauma and Orthopaedics, Leeds Teaching Hospitals, Leeds, United Kingdom, Phone: +44-113-3922750, e-mail: paulharwood@nhs.net

How to cite this article: Giannoudis VP, Ewins E, Taylor DM, et al. Clinical and Functional Outcomes in Patients with Distal Tibial Fracture Treated by Circular External Fixation: A Retrospective Cohort Study. Strategies Trauma Limb Reconstr 2021;16(2):86-95.

Source of support: Nil

Conflict of interest: None

\section{Materials and Methods}

Cases were identified from our prospective limb reconstruction database. Consecutive adult patients (16-year-old or greater) with tibial fractures extending to within 1 Müller square of the ankle joint treated with llizarov frames between August 1, 2011, and August 1, 2016, were included. Information contained in the database was supplemented by a review of clinical records. Fracture pattern was classified according to the Arbeitsgemeinschaft für

(-) Jaypee Brothers Medical Publishers. 2021 Open Access This article is distributed under the terms of the Creative Commons Attribution-Non Commercial-share alike license (https://creativecommons.org/licenses/by-nc-sa/4.0/) which permits unrestricted distribution, and non-commercial reproduction in any medium, provided you give appropriate credit to the original author(s) and the source, provide a link to the Creative Commons license, and indicate if changes were made. If you remix, transform, or build upon the material, you must distribute your contributions under the same license as original. The Creative Commons Public Domain Dedication waiver (http://creativecommons.org/publicdomain/zero/1.0/) applies to the data made available in this article, unless otherwise stated. 
Osteosynthesefragen / Orthoapedic Trauma Association (AO/OTA) system with fractures designated as intra-or extra-articular $(A, B, \operatorname{or} C)$ and their complexity as 1,2 , or $3 .{ }^{10}$ Open injuries were classified according to Gustilo and Anderson after debridement. ${ }^{11}$ Union was defined as bony bridging of at least three of four cortices on plain radiology or computed tomography and full weight-bearing without symptoms during follow-up, following frame removal. Alignment at union was assessed by measuring the lateral and anterior distal tibial angles (LDTA and ADTA) with acceptable alignment defined as 84 to $94^{\circ}$ for the coronal and 70 to $90^{\circ}$ for the sagittal planes. ${ }^{12}$ Joint surface reduction was assessed at union according to Ovadia and Beals. ${ }^{13}$ Radiographic ankle arthritis was graded according to the Takakura classification as absent (grade 0), mild (grade 1-early sclerosis and osteophyte formation, no joint space narrowing), moderate (grade 2-joint space narrowing without subchondral bone contact), or severe (grade 3 or 4-any obliteration of joint space) on most recent radiographs. ${ }^{14}$ Adverse events were classified as problems (resolved by the time of frame removal, managed non-operatively), obstacles (resolved by the time of frame removal, managed operatively), and complications (having long-term implications). ${ }^{15}$ Complications were subclassified as minor, major not affecting goals of treatment (major-NA), and major affecting goals of treatment (major-A).

\section{Functional Outcome Scores}

Since 2013, the patient-reported functional outcome data have been routinely collected at 3 and 12 months after frame removal. This includes the Olerud and Molander (O\&M) ankle score, ${ }^{16}$ the Lysholm knee score, ${ }^{17}$ and the Euroqol 5 dimensions questionnaire. ${ }^{18}$ Patients in whom these data were missing were sent identical postal questionnaires for completion. Functional outcome data were divided into those measured less than 6 months after frame removal and more than 6 months following frame removal.

\section{Clinical Management}

At presentation, fractures were initially stabilised using a plaster back-slab. Where early definitive fixation was either inappropriate or unavailable, a spanning external fixator was applied if the fracture was felt to be mechanically unstable. ${ }^{19}$ Open fractures and compartment syndrome were managed according to British Orthopaedic Association Standards for Trauma (BOAST)-4 and BOAST-10 guidelines utilising a combined orthoplastic approach. ${ }^{8,20}$
In these patients, Ilizarov fixation was usually delayed until the soft tissue envelope was secure. Joint surface reduction and stabilisation was were undertaken at definitive soft tissue cover where necessary using cannulated lag screws. Patients with segmental bone loss due to open injury were treated by distraction osteogenesis using the llizarov fixator.

Definitive fracture stabilisation was achieved using a consistent operative approach. ${ }^{5,21}$ For intra-articular injuries, closed joint surface reduction was initially attempted by distraction capsuloligamentotaxis. Where unsuccessful, percutaneous or formal open reduction was undertaken via incisions based upon cross sectional radiology. The aim was to achieve as close to anatomic reduction as possible without jeopardising the injured soft tissue envelope. The metaphysis was stabilised using multiple olive wires and $4 \mathrm{~mm}$ partially threaded cannulated screws as required. Two llizarov rings with at least two fixation elements each were placed on the proximal fragment, aligned with its axis. The metaphyseal block was reduced to this initial construct. At least four wires on one or two rings, including transfibular fixation, were placed on the metaphyseal segment. Static ankle span to the calcaneum was added for instability or severe joint surface comminution in selected cases (this being removed at around 6 weeks). Where significant metaphyseal comminution existed, an additional ring was placed to allow reduction and stabilisation of large butterfly fragments. Examples of different fracture patterns treated as detailed above are shown in Figures 1 to 3.

Patients were mobilized with unrestricted weight-bearing and range of motion. Pin-site care was according to the Royal College of Nursing consensus guidelines. ${ }^{22}$ Routine follow-up was at 2 weeks post frame application and then every 4-6 weeks until union. Once radiographic union occurred, frames were destabilised by disconnecting the rings across the fracture for 1 week. If significant deterioration in symptoms occurred frames were restabilised and the process repeated in 4-6 week's. Otherwise, the fracture was deemed to have united and the frame removed. Following this, patients were seen at 6-12 weeks postframe removal and then at 12 months postframe removal and discharged if all was well.

\section{Statistical Analysis}

Statistical analysis was carried out using Analyse-it for Microsoft Windows (Version 4-http://www.analyse-it.com). Assumptions
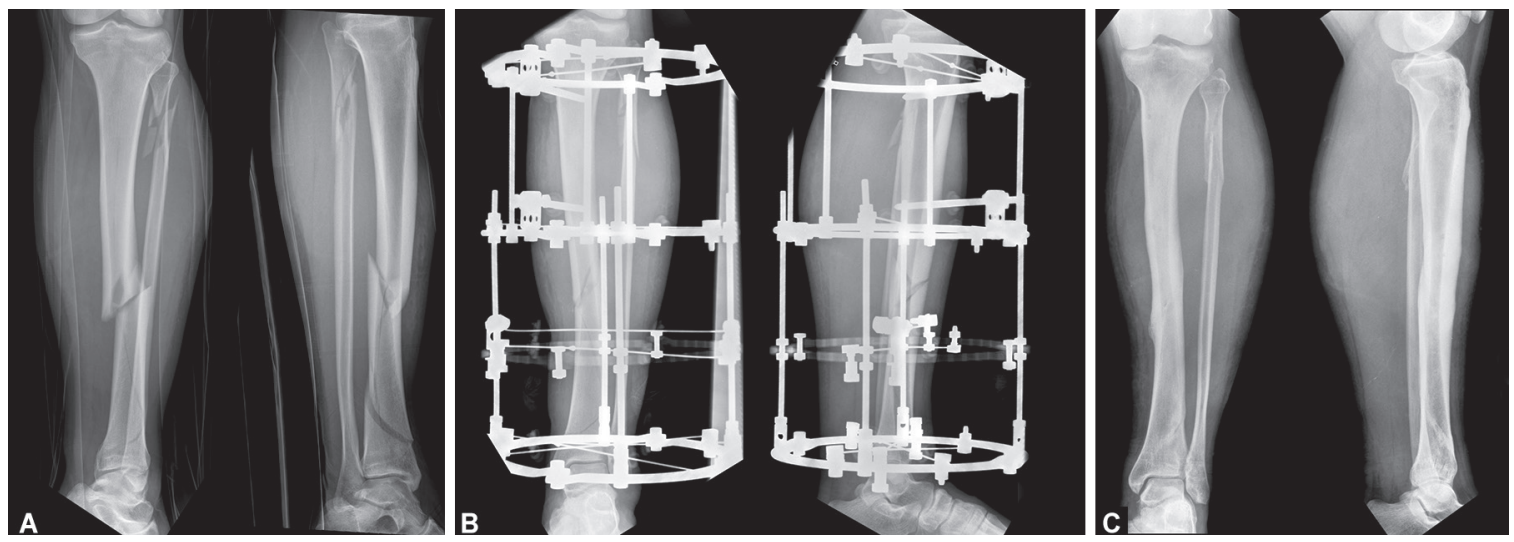

Figs $1 \mathrm{~A}$ to $\mathrm{C}$ : Extra-articular distal tibial fracture. Closed fracture with significant soft tissue swelling and blistering due to high-speed rollerblading accident. (A) Preoperative anteroposterior and lateral radiographs; (B) Anteroposterior and lateral radiographs following stabilisation with a circular frame; (C) Anteroposterior and lateral radiographs at 18 months postinjury (fracture united and frame removed after 22 weeks) 


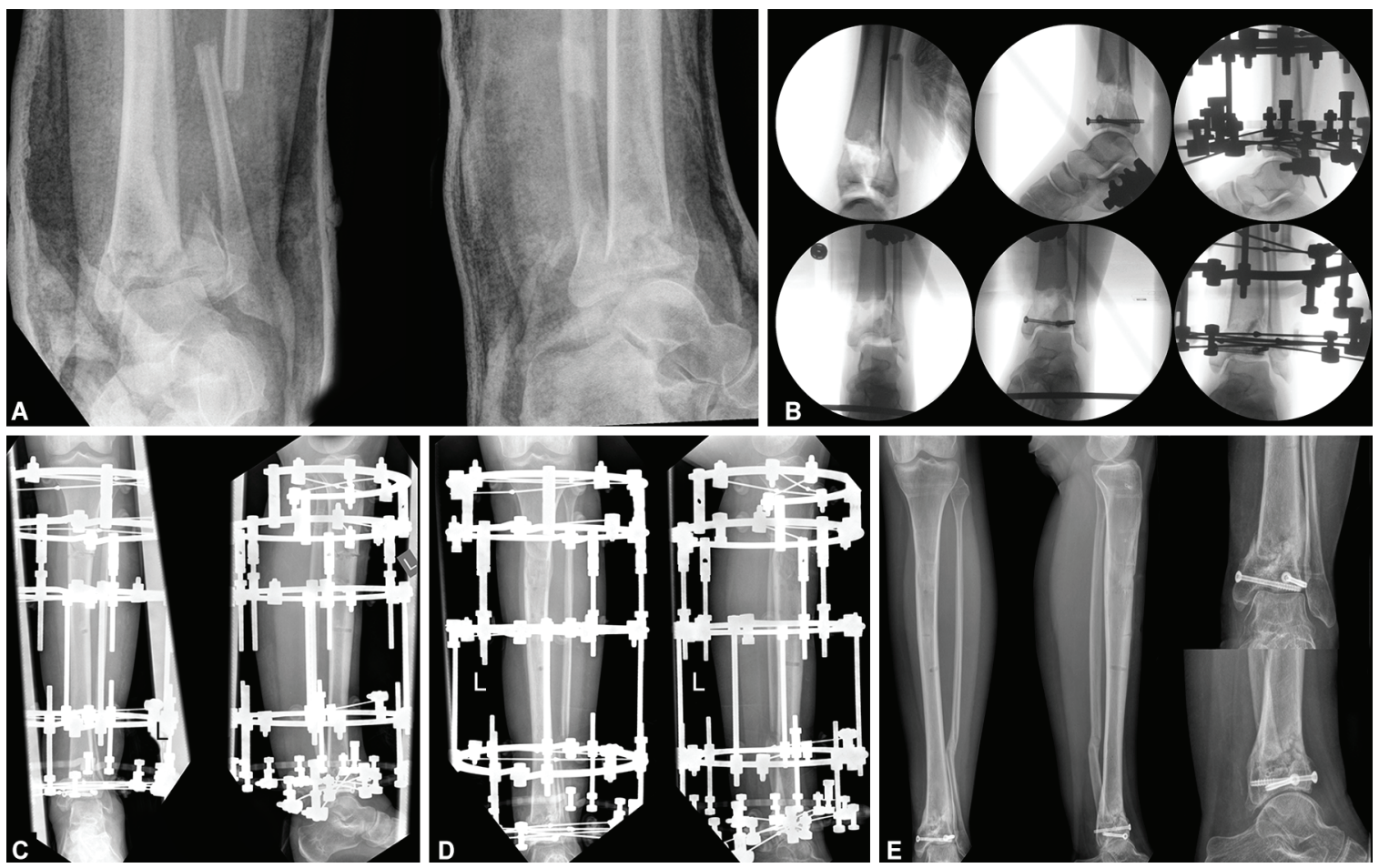

Figs 2A to E: High energy open total articular distal tibial fracture. (A) Preoperative AP and lateral radiographs; (B) Intraoperative radiographs from definitive management showing joint surface reduction-(left) after debridement with the application of traction for capsuloligamentotaxis, (middle) after open reduction and insertion of two cannulated lag screws, and (right) following completion of fixation and shortening of bone defect to achieve contact; (C) Anteroposterior and lateral radiographs after primary treatment. Following debridement, there was $5 \mathrm{~cm}$ of metaphyseal bone loss. The patient has undergone reduction and stabilisation of the joint surface, acute shortening, soft tissue cover, application of a circular frame, and staged corticotomy for relengthening (8 weeks postinjury); (D) Anteroposterior and lateral radiographs after the patient has completed lengthening; (E) Final anteroposterior and lateral radiographs of tibia and ankle 1-year postframe removal (fracture and regenerate united and frame removed 7 months postinjury)
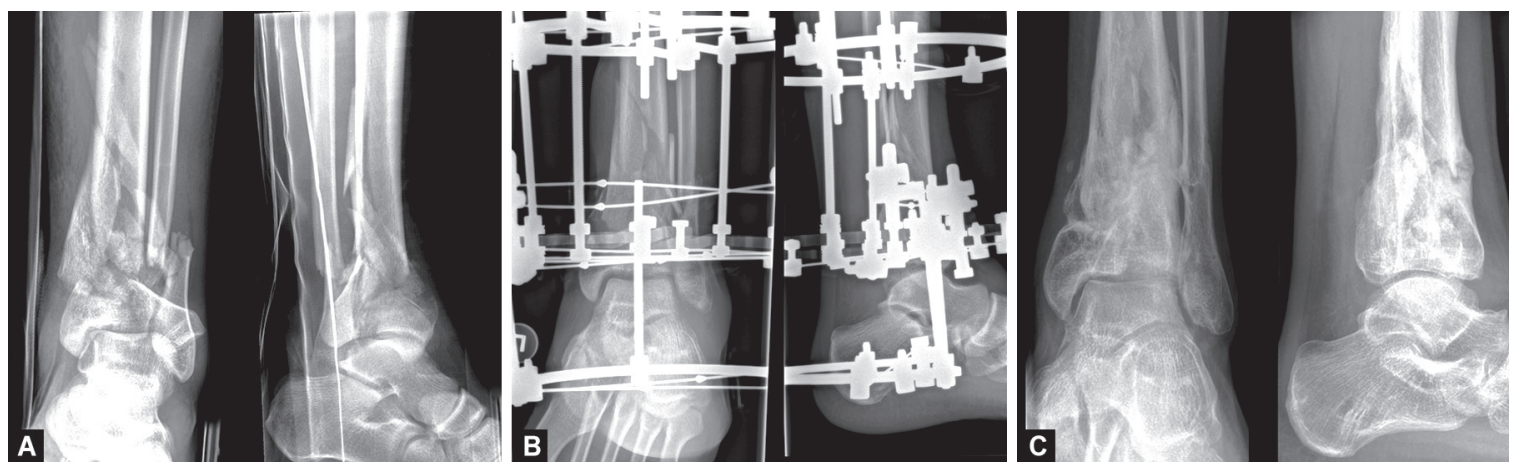

Figs 3A to C: High energy closed total articular distal tibial fracture. (A) Anteroposterior and lateral radiographs showing severe joint surface disruption; (B) Anteroposterior and lateral radiographs following open reduction and application of circular frame. Ankle span was maintained for 6 weeks; (C) Anteroposterior and lateral radiographs at last follow-up 4 years postinjury. Patient has developed radiographic osteoarthritis despite good joint surface reduction but has maintained function, returned to work, and complains of loss of motion rather than pain

for parametric analysis were not met; therefore, central tendency is described as a median and spread by the interquartile range (IQR) and absolute range where helpful. Nonparametric methods (Mann-Whitney U, Kruskal-Wallis, Wilcoxon paired, and Spearman's rank tests) were used to examine relationships between variables. Nominal variables were compared using Chi-squared and Fisher's exact tests as appropriate. Where specific variables were missing, the patient was excluded from that analysis. Statistical significance was assumed at the $p<0.05$ level..$^{23}$ The manuscript was written with reference to the STROBE statement. ${ }^{24}$

\section{RESULTS}

\section{Demographics and Injury Pattern}

One hundred and sixty-eight patients with 169 fractures were identified. All had completed follow-up to union and were included 


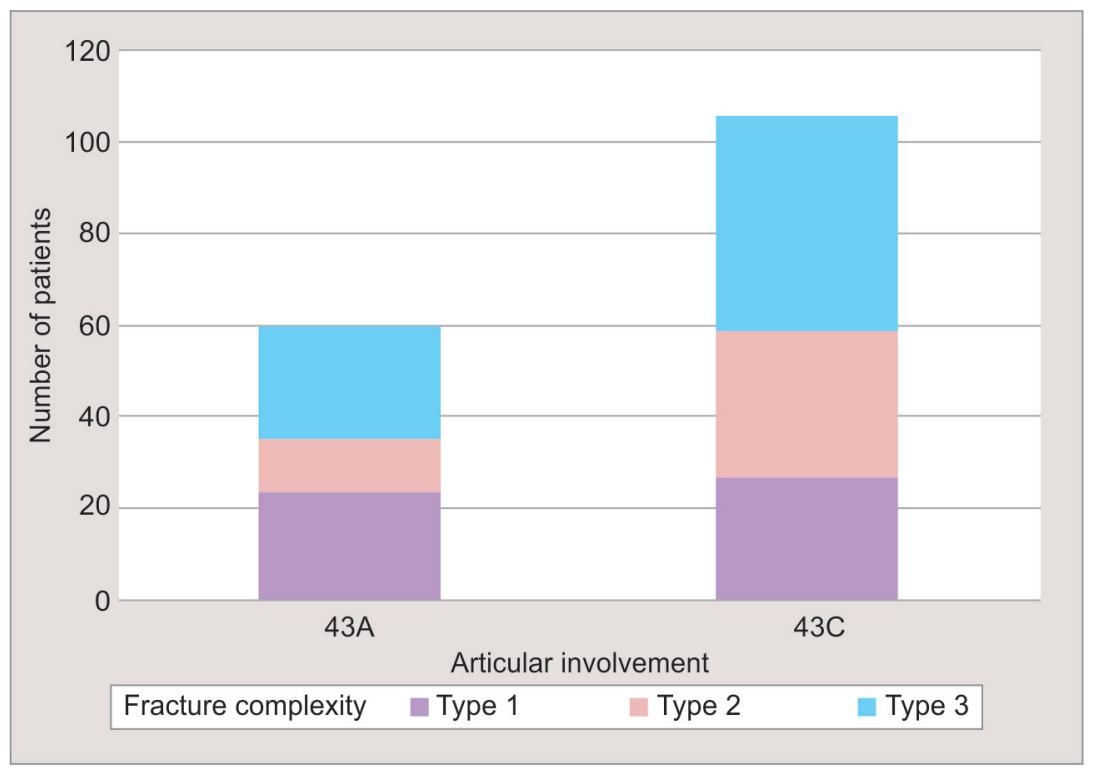

Fig. 4: Distribution of fracture type according to the AO classification. $43 \mathrm{~A}$ extra-articular fractures- 1 simple, 2 wedge, and 3 complex. $43 \mathrm{C}$ complete articular-1 simple articular and metaphyseal, 2 complex metaphyseal, simple articular, 3 complex articular (one 43B and two 42 type fractures extending to distal metaphysis not shown)

in the final analysis. Sixty-eight percent of patients were male, the median age at injury was 44 years (IQR, 34-55; range, 16-88 years). One hundred and thirty-four patients had isolated injuries (80\%), $22(13 \%)$ had other extremity trauma, and $26(15 \%)$ multisystem trauma. The median injury severity score was 4 (IQR, 4-9; range, 4-50). Fifty-nine percent had been referred to our department for specialist treatment from elsewhere.

Distribution of fracture type is shown in Figure 4; in addition, two fractures were classified as $42 \mathrm{C}$ injuries with distal tibial metaphyseal extension, and there was a single $B$ type injury. Most fractures were intra-articular (107-63\%), a significant proportion being complex articular (46-28\% AO43C3-Pilon fractures). Forty-seven (28\%) of the fractures were open; of these, $30(63 \%)$ were Gustilo and Anderson grade IIIA and 17 (37\%) grade IIIB. Most fractures were complex, as reflected by the AO classification, $28 \%$ being type 2 and $44 \%$ type 3 .

\section{Treatment}

The median time between injury and frame application was 9 days (IQR, 6-14; range, $0-82$ ) with 15 patients having definitive fixation in the first 48 hours. In eight patients, fixation was delayed by more than 21 days, in three due to concerns about their soft tissue envelope. The five remaining patients had initial treatment elsewhere (two non-operative, two with ring, and one a monolateral fixator). These were all revised early due to significant malreduction. In three of these patients, a hexapod fixator was used to allow gradual correction. All patients other than these revision cases and those treated acutely had spanning external fixators applied prior to definitive surgery. Of the 17 Gustilo and Anderson IIIB open fractures, cover was achieved using free tissue transfer in six (35\%), fasciocutaneous flaps in four (24\%), and partial closure and split skin graft in three (18\%). In the remaining four patients, associated bone loss was managed by acute shortening which facilitated direct closure of the open wounds. In total six patients suffered segmental bone loss, all initially managed by acute shortening.
Four of these patients underwent successful re-lengthening by distraction osteogenesis. In the remaining two patients, one had a pre-existing contralateral leg length discrepancy and the shortening resulted in equalisation of limb length, the other had suffered a significant traumatic brain injury with limited functional recovery. In both patients, it was elected, therefore, to accept the shortening. The 29 Gustilo and Anderson IIIA injuries were closed primarily. Of the 107 articular injuries, screws were used to augment the metaphyseal fixation in $50(47 \%)$ patients overall. There was no significant difference in the rate of their use between simple (C1/2) and complex (C3) injuries (49 vs 44\%). Of the 62 extra-articular injuries, three had spanning ankle fixation applied. This was due to a low fibula fracture in one and very distal fracture extension with metaphyseal comminution in the others, to improve sagittal plane stability. Forty-eight (45\%) of the patients with intra-articular injuries had their ankles spanned. This was undertaken more commonly in the patients with complex (43C3) injuries than those with other articular fracture patterns ( 70 vs $26 \%$, Fisher's exact test $p<0.0001$ ). The spanning fixation was removed at 6-8 weeks in all cases.

\section{Clinical Outcomes}

\section{Union and Time to Union}

One hundred and sixty-three (96\%) fractures united without further surgical intervention to aid union. Two patients underwent unplanned bone grafting and six non-operative fracture site stimulation (distraction or Exogen), all subsequently uniting. Therefore, 165 (98\%) fractures united in their primary Ilizarov fixators at a median of 166.5 days following injury (IQR, 138-203; range, 104-537). Figure 5 shows cumulative progression to the union over time, $62 \%$ uniting by 6 months, $89 \%$ by 9 months, and $96 \%$ by 1 year. Open fractures took longer to unite than closed [median, 158 (IQR, 133-199) vs 183 (IQR 159-220); $p<0.01]$. (AO/OTA) group 3 severity fractures took longer to unite (median, 183 days; IQR, 162-221) than group 1 


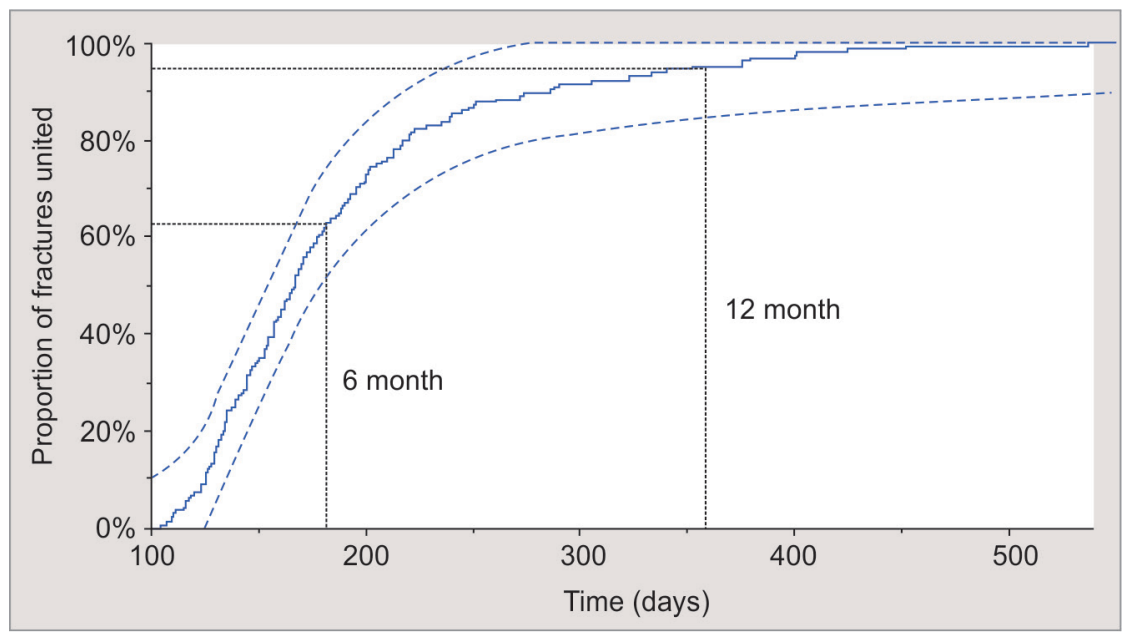

Fig. 5: Proportion of fractures united over time. Sixty-two percent united by 6 months and $96 \%$ by 1 year. The dashed line represents $95 \%$ confidence interval

[median, 144 days (IQR, 126-178)] and 2 (median, 157 days; IQR, 141-192) [ $p<0.0001$; Kruskal-Wallis test with Tukey post hoc analysis ( $p<0.05$ for group 2 vs 3 and $p<0.005$ for group 1 vs 3 )]. No other factor was significantly associated with time to union.

\section{Radiographic Outcomes}

One hundred and sixty of the 168 fractures (95\%) united within 5 degrees of population average LDTA, only one patient had coronal plane malalignment of more than 10 degrees. One hundred and sixty-two fractures (96\%) united within 10 degrees of the population average ADTA. Of the articular injuries, joint surface reduction was graded as good (O\&B score, $>12$ ) in 114 (98\%) and fair (O\&B score, 7-12) in two patients. In no patients, it was graded as poor. All patients with simple articular injuries had a score of $18 / 18$. When considering those with complex articular injuries, the median O\&B score remained 18/18 (IQR, 16-18; range, 7-18). One hundred and thirty-seven patients had ankle radiographs more than 12 months postinjury (Median, 20; IQR, 17-24). Of these, 38 (28\%) had signs of OA, graded as mild in 24 , moderate in 9 , and severe in 5 . The development of arthritic change was very unusual in extra-articular injuries (3 of 52 patients with mild changes only). We found no relationship between coronal or sagittal alignment and the development of OA. Of the 84 articular fractures in this group, 21 (25\%) developed mild, $9(11 \%)$ moderate, and $5(6 \%)$ severe OA changes. This was more common and more severe in those with complex articular injury patterns ( $\mathrm{AO} 43 \mathrm{C} 3$ ) compared with other articular injuries (mild OA 15 vs 39\%, moderate 4 vs 19\%, and severe 0 vs 14\%; Chisquared test, $p<0.0001)$. Those with OA graded as moderate or severe had significantly lower O\&B scores (Kruskal-Walis test, $p<0.0001$; Dunnett comparison against no OA, $p=0.04$ for moderate and $p<0.0001$ for severe).

\section{Adverse Events and Unexpected Additional Interventions}

Details of adverse events are found in Table 1. The most severe adverse event encountered was a problem in 53 patients (31\%), an obstacle in 14 patients (8\%), and a complication in 19 patients (11\%). Thirty-one patients (18\%) underwent unplanned surgical intervention, three required two procedures, and two three procedures. In addition to the operations detailed elsewhere, two patients underwent removal of internal fixation screws, one a fusion for arthritis and one a pin-site release postframe removal.

\section{Non-union}

Two fractures required bone grafting to achieve union and four failed to unite in their original frames (Table 2). Three of these nonunions have subsequently united with further treatment. The final patient, a diabetic with severe peripheral neuropathy, elected to undergo early transtibial amputation after repeated complications.

\section{Infection}

Sixty-five patients (39\%) suffered pin-site infections, largely resolved by oral antibiotics. Four patients had fixation elements replaced after failing to respond to non-operative treatment. Eight patients (5\%) suffered a deep infection. In four, this was a persistently discharging pin site following frame removal, treated by over-drilling and oral antibiotics with no sign of recurrence on further follow-up (Table 1). Four patients suffered more significant infections (Table 3). At final follow-up, all patients are currently infection-free.

\section{Other Significant Adverse Events}

Four patients suffered thrombotic events which have not resulted in long-term sequelae. Two patients suffered complex regional pain syndrome, this has resolved in one and is persistent in the other. One patient suffered a low-energy fracture at the level of a previous wire in the proximal fragment, successfully treated with a second llizarov frame. One patient had a significant malunion (18 degrees valgus). Having requested frame removal before union and then removed their cast against advice, the fracture lost position then united. Though revision surgery was planned, they have subsequently failed to attend follow-up and have been discharged.

\section{Patient-reported Outcome Measures}

Functional outcome data were incomplete. One hundred and fourteen (67\%) patients had scores recorded overall, $67(40 \%)$ in the first 6 months (median, 59 days; IQR, 42-89) and 87 (51\%) more than 6 months after frame removal (median, 401 days; IQR, 367-556). Forty patients had scores recorded at both time points. Patients 
Outcomes in Distal Tibial Fractures Treated by Circular External Fixation

Table 1: Adverse events suffered by patients classified according to Paley

\begin{tabular}{|c|c|c|c|}
\hline Classification & Number of patients & Event & Number \\
\hline \multirow[t]{5}{*}{ Problem } & \multirow[t]{5}{*}{$72(43 \%)$} & Pin-site infection & 65 \\
\hline & & Non-operative fracture stimulation & 6 \\
\hline & & Allergy/eczema (pre-existing in 3) & 12 \\
\hline & & Wire removal or repair & 9 \\
\hline & & Wound breakdown & 1 \\
\hline Obstacle & $17(10 \%)$ & Wire exchange & 17 \\
\hline Complication & $19(11 \%)$ & & \\
\hline \multirow[t]{4}{*}{ Minor } & \multirow[t]{4}{*}{$9(5 \%)$} & VTE & 4 \\
\hline & & CRPS & 2 \\
\hline & & Deep pin-site infection & 4 \\
\hline & & Heel abscess related to monolateral exfix & 1 \\
\hline \multirow[t]{3}{*}{ Major-NA } & \multirow[t]{3}{*}{$5(3 \%)$} & Deep infection (one septic knee, one fracture site) & 2 \\
\hline & & Unplanned bone graft to achieve union & 2 \\
\hline & & Refracture (pin site) & 1 \\
\hline \multirow[t]{3}{*}{ Major-A } & \multirow[t]{3}{*}{$5(3 \%)$} & Non-union & 3 \\
\hline & & Amputation & 1 \\
\hline & & Significant malunion & 1 \\
\hline $\begin{array}{l}\text { Non-operative } f \\
\text { eczema was a } r \\
\text { embolism-3 lo } \\
\text { Deep pin-site in } \\
\text { classification, } m \\
\text { affecting the go }\end{array}$ & $\begin{array}{l}\text { e stimulation was by } \\
\mathrm{n} \text { to dressings in } 9 \text { a } \\
\mathrm{mb} \text { deep vein thromb } \\
\mathrm{n} \text { all remote to fractu } \\
\text { J-major complica } \\
\text { treatment }\end{array}$ & $\begin{array}{l}\text { W-intensity pulsed ultrasound in } 3 \text { and frame manipula } \\
\text { exacerbation of a pre-existing condition in } 3 \text {. VTE- } \\
\text { es and } 1 \text { pulmonary embolism. CRPS-complex region } \\
1 \text { calcaneal from spanning exfix, } 3 \text { tibial from llizarov w } \\
\text { n not affecting the goals of treatment, major-A-ma }\end{array}$ & $\begin{array}{l}\text { 3. Allergy, } \\
\text { thrombo } \\
\text { syndrome } \\
\text { mplication } \\
\text { mplication }\end{array}$ \\
\hline
\end{tabular}

Table 2: Details of patients with non-unions

\begin{tabular}{|c|c|c|c|}
\hline Injury details & Co-morbidities & Non-union details & Outcome \\
\hline $\begin{array}{l}\text { Closed severe pilon fracture } \\
\text { following crush injury with } \\
\text { compartment syndrome }\end{array}$ & None & $\begin{array}{l}\text { Fracture slow to progress to } \\
\text { union }\end{array}$ & $\begin{array}{l}\text { Bone grafted in the original } \\
\text { frame-united }\end{array}$ \\
\hline $\begin{array}{l}\text { GA IIIA open severe pilon } \\
\text { fracture with partial bone loss }\end{array}$ & $\begin{array}{l}\text { Alcohol misuse, poor } \\
\text { compliance }\end{array}$ & $\begin{array}{l}\text { Fracture slow to progress to } \\
\text { union. No evidence of bridging } \\
\text { of sub-segmental defect }\end{array}$ & $\begin{array}{l}\text { Bone graft to defect in } \\
\text { original frame-united }\end{array}$ \\
\hline Closed, extra-articular fracture & None & $\begin{array}{l}\text { Hypertrophic non-union } \\
\text { following frame removal after } \\
\text { apparently successful treatment }\end{array}$ & $\begin{array}{l}\text { Successfully treated by closed } \\
\text { manipulation with a hexapod } \\
\text { fixator } \\
\text { Returned to full activity including } \\
\text { sport }\end{array}$ \\
\hline $\begin{array}{l}\text { GA IIIB open fracture treated by } \\
\text { debridement and split skin graft } \\
\text { prior to transfer for definitive } \\
\text { frame }\end{array}$ & None & Infected non-union & $\begin{array}{l}\text { Successfully treated by segmental } \\
\text { resection and bone transport }\end{array}$ \\
\hline $\begin{array}{l}\text { GA IIIA open OA/OTA } 43 C 3 \\
\text { fracture }\end{array}$ & $\begin{array}{l}\text { Previously undiagnosed } \\
\text { recalcitrant thyrotoxicosis } \\
\text { Polytrauma with an abdominal } \\
\text { injury and bowel resection }\end{array}$ & $\begin{array}{l}\text { Atrophic non-union with bone } \\
\text { resorption } \\
\text { Bone catabolic state related to } \\
\text { thyrotoxicosis } \\
\text { No evidence of deep infection }\end{array}$ & $\begin{array}{l}\text { Thyroidectomy led to } \\
\text { normalization of bone profile } \\
\text { Successful treatment of non- } \\
\text { union by internal fixation and } \\
\text { induced membrane technique }\end{array}$ \\
\hline Closed, extra-articular fracture & $\begin{array}{l}\text { Poorly controlled, complicated } \\
\text { type I diabetes } \\
\text { Insensate limb due to peripheral } \\
\text { neuropathy }\end{array}$ & $\begin{array}{l}\text { Recurrent loss of fixation } \\
\text { Developed ulceration on foot }\end{array}$ & $\begin{array}{l}\text { Elected to undergo transtibial } \\
\text { amputation } \\
\text { Has regained mobility with } \\
\text { prosthetic }\end{array}$ \\
\hline
\end{tabular}

with functional outcome scores available were significantly older (median, 41 vs 47 years) than those in whom these scores were missing. There were no other statistically significant differences between these groups for any recorded variables.
The median Lysholm knee score at less than 6 months was 89 (IQR, 74-94) compared with 93 at more than 6 months (IQR, 81-98), this difference did not reach statistical significance (Wilcoxon test, $p=0.06$ ). In contrast, the O\&M ankle score improved from a 
Table 3: Details of patients with deep infection other than ring sequestrum

\begin{tabular}{|c|c|c|c|}
\hline Injury details & Co-morbidities & Infection details & Outcome \\
\hline $\begin{array}{l}\text { Closed, extra-articular } \\
\text { fracture }\end{array}$ & None & $\begin{array}{l}\text { Recurrent fracture site hematoma, } \\
\text { became infected clinically }\end{array}$ & $\begin{array}{l}\text { Successfully treated by drainage, } \\
\text { debridement, and free flap. Went on } \\
\text { to an uneventful union following this }\end{array}$ \\
\hline $\begin{array}{l}\text { GA IIIB open fracture treated } \\
\text { by debridement and split } \\
\text { skin graft prior to transfer for } \\
\text { definitive frame }\end{array}$ & None & Infected non-union & $\begin{array}{l}\text { Successfully treated by segmental } \\
\text { resection and bone transport }\end{array}$ \\
\hline GA IIIB open with bone loss & $\begin{array}{l}\text { Polytrauma with a severe head } \\
\text { injury. Prolonged period on ICU. } \\
\text { Infected surgical site } \\
\text { following internal fixation } \\
\text { proximal humerus }\end{array}$ & $\begin{array}{l}\text { Septic arthritis of knee ipsilateral to } \\
\text { frame-apparently not related to } \\
\text { frame-no pin site infection, no pin } \\
\text { sites in or near to capsular } \\
\text { reflections of knee }\end{array}$ & $\begin{array}{l}\text { Successfully treated by arthroscopic } \\
\text { washout and antibiotics without } \\
\text { revision of frame or removal of pins. } \\
\text { Went on to union without further } \\
\text { septic complication }\end{array}$ \\
\hline $\begin{array}{l}\text { GA IIIA open intra-articular } \\
\text { fracture }\end{array}$ & None & $\begin{array}{l}\text { Collection related to calcaneal from } \\
\text { spanning external fixator (early) }\end{array}$ & $\begin{array}{l}\text { Successfully treated by surgical } \\
\text { drainage, over-drilling of pin site, and } \\
\text { local antibiotics }\end{array}$ \\
\hline
\end{tabular}

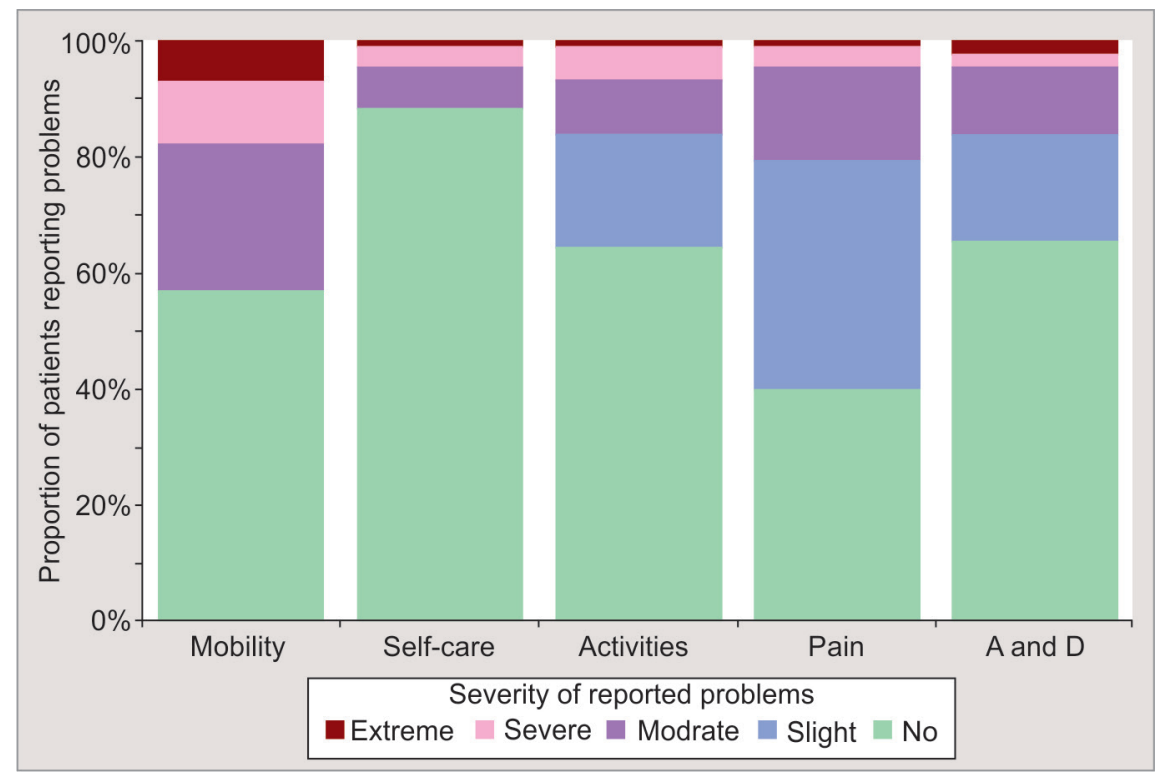

Fig. 6: Proportion of patients reporting problems in different EuroQol domains at more than 6 months post frame removal $(n=87)$ A and D-anxiety and depression

median of 55 (IQR, 35-70) in the first 6 months to 73 (IQR, 55-90) (Wilcoxon test, $p<0.001$ ). This equated to an increase in the proportion of patients rated as good or excellent from 38 to $62 \%$, those rated as poor fell from 20 to $10 \%$ (Chi-squared test, $p<0.05$, 3d.f.). The median EuroQol visual analog score (VAS) improved from 80 (IQR, 65-88) to 85 (75-95) (Wilcoxon test, $p=0.01$ ). Figure 6 summarises EuroQol ratings for different domains in patients completing outcome forms at more than 6 months post frame removal. Table 4 shows the association of various injury factors with functional outcomes measured at more than 6 months post frame removal. Articular injuries, particularly $43 C 3$ injuries, and the development of radiographic OA were associated with worse O\&M ankle scores. Considering only those with articular injuries (52 patients), a statistically significant relationship between the Ovadia and Beals score for joint reduction and O\&M ankle scores was found (Spearman's rank, $r s=0.33$ and $p=0.02$ ). No other significant relationships between these scores and other variables were detected.

\section{Discussion}

The management of distal tibial fractures is challenging. To our knowledge, this study describes the largest series of adult patients with distal tibial fractures treated by the llizarov method published to date. The aim of this study was to assess clinical and functional outcomes following distal tibial fractures treated in this manner in our unit. We chose to include patients with intra- and extraarticular injuries as these injuries share the potential risks of surgical intervention in an area with a relatively poor soft tissue envelope. An excess of complications has been reported following internal fixation compared with other sites. Our findings suggest definitive llizarov fixation is a safe and effective approach to these injuries. Outcome scores, however, demonstrate a significant ongoing 
Outcomes in Distal Tibial Fractures Treated by Circular External Fixation

Table 4: Factors associated with different functional outcome measures recorded at greater than 6 months post frame removal $(n=87)$

\begin{tabular}{|c|c|c|c|c|c|c|c|c|c|}
\hline \multirow{2}{*}{$\begin{array}{l}\text { Factor } \\
\text { Open fracture }\end{array}$} & \multicolumn{3}{|c|}{ Lysholm score } & \multicolumn{3}{|c|}{ O\&M score } & \multicolumn{3}{|c|}{ EuroQol VAS } \\
\hline & $\begin{array}{l}\text { Yes } \\
89 \\
(80-93)\end{array}$ & $\begin{array}{l}\text { No } \\
93 \\
(84-100) \\
p=0.06 \\
\end{array}$ & & $\begin{array}{l}\text { Yes } \\
65 \\
(50-80)\end{array}$ & $\begin{array}{l}\text { No } \\
80 \\
(55-90) \\
p=0.11\end{array}$ & & $\begin{array}{l}\text { Yes } \\
80 \\
(69-90)\end{array}$ & $\begin{array}{l}\text { No } \\
85 \\
(76-95) \\
p=0.24\end{array}$ & \\
\hline $\begin{array}{l}\text { Intra-articular } \\
\text { fracture }\end{array}$ & $\begin{array}{l}\text { Yes } \\
93 \\
(81-96)\end{array}$ & $\begin{array}{l}\text { No } \\
92 \\
(80-100) \\
p=0.69 \\
\end{array}$ & & $\begin{array}{l}\text { Yes }^{*} \\
65 \\
(48-81)\end{array}$ & $\begin{array}{l}\mathrm{No}^{*} \\
80 \\
(63-90) \\
p=0.02\end{array}$ & & $\begin{array}{l}\text { Yes } \\
85 \\
(75-95)\end{array}$ & $\begin{array}{l}\text { No } \\
85 \\
(70-90) \\
p=0.58\end{array}$ & \\
\hline AO severity & $\begin{array}{l}1 \\
93 \\
(80-98)\end{array}$ & $\begin{array}{l}2 \\
95 \\
(89-100)\end{array}$ & $\begin{array}{l}3 \\
92 \\
(79-95) \\
p=0.26\end{array}$ & $\begin{array}{l}1 \\
80 \\
(63-87)\end{array}$ & $\begin{array}{l}2 \\
82.5 \\
(60-90)\end{array}$ & $\begin{array}{l}3 \\
60 \\
(46-80) \\
p=0.07\end{array}$ & $\begin{array}{l}1 \\
90 \\
(77-95)\end{array}$ & $\begin{array}{l}2 \\
90 \\
(74-98)\end{array}$ & $\begin{array}{l}3 \\
80 \\
(75-90) \\
p=0.09\end{array}$ \\
\hline $\begin{array}{l}\text { Pilon fracture } \\
(\mathrm{AO} 43 \mathrm{C} 3)\end{array}$ & $\begin{array}{l}\text { Yes } \\
92 \\
(80-94)\end{array}$ & $\begin{array}{l}\text { No } \\
94 \\
(81-100) \\
p=0.19\end{array}$ & & $\begin{array}{l}\text { Yes }^{*} \\
55 \\
(35-66)\end{array}$ & $\begin{array}{l}\mathrm{No}^{*} \\
80 \\
(62-81) \\
p=0.000\end{array}$ & & $\begin{array}{l}\text { Yes }^{*} \\
80 \\
(70-87)\end{array}$ & $\begin{array}{l}\mathrm{No}^{*} \\
90 \\
(77-95) \\
p=0.02\end{array}$ & \\
\hline $\begin{array}{l}\text { OA moderate or } \\
\text { SEVERE }\end{array}$ & $\begin{array}{l}\text { Yes } \\
86 \\
(69-93)\end{array}$ & $\begin{array}{l}\text { No } \\
93 \\
(84-99) \\
p=0.11\end{array}$ & & $\begin{array}{l}\text { Yes }^{*} \\
37.5 \\
(32-55)\end{array}$ & $\begin{array}{l}\mathrm{No}^{*} \\
75 \\
(60-90) \\
p=0.002\end{array}$ & & $\begin{array}{l}\text { Yes } \\
80 \\
(64-88)\end{array}$ & $\begin{array}{l}\text { No } \\
85 \\
(75-95) \\
p=0.27\end{array}$ & \\
\hline
\end{tabular}

Median and IQR shown, statistical significance according to Mann-Whitney $\mathrm{U}$ or Wilcoxon test as appropriate. ${ }^{*}$ Result statistically significant $p<0.05$

impact on quality of life and limb function at more than 6 months post frame removal.

Despite high rates of open and complex fractures in our study, bony union was achieved in $98 \%$ of patients in their initial frame and $96 \%$ without additional surgical procedures to stimulate union. Pooled analysis of previous studies suggests non-union rates following external fixation for distal tibial fracture to be around $5-8 \% .{ }^{25,26}$ However, rates in individual studies vary, with smaller series reporting non-union in $10-40 \%$ of patients. ${ }^{3,25,27,28}$ Previous meta-analyses also suggest non-union rates in our series compare favorably with patients treated for distal tibial fracture by internal fixation, with non-union occurring in 2-9\%. ${ }^{26,29-32}$ These figures are not markedly different between studies including intra- and extraarticular fractures. Such results are, however, difficult to interpret due to the diverse nature of the patients and treatment methods employed, making pooled analysis troublesome and its results potentially unreliable. ${ }^{25,33}$

The deep infection rate of 5\% in this series also compares well with that reported for other forms of treatment in both intra- and extra-articular fractures, with individual studies reporting rates of up to $40 \% .^{25,33,34}$ This is particularly striking considering the complexity of our cases and that half the patients with infection had a ring sequestrum remote from the fracture, successfully treated by simple over-drilling. Indeed only two patients (1\%) had a deep infection at the fracture site (Table 3). Previous pooled analysis suggests that deep infection following external fixation for distal tibial fracture occurred in $5-8 \%$ of cases. ${ }^{25,26}$ Pooled rates of $3-16 \%$ have been reported following plate fixation and $3-8 \%$ for intramedullary nailing (IMN). ${ }^{25,26,30-32,35}$ Reported rates in the studies included in these analyses vary greatly, and again, concerns about data quality exist. The FixDT trial, arguably the most robust study examining outcomes in patients with distal tibial fracture, reports an extremely low deep infection rate in patients treated by internal fixation for extra-articular distal tibial fractures. Two percent of patients overall and only 1 of 161 in the nailing group required surgical debridement following fixation by 1 year. ${ }^{7}$ Rates of non-operatively managed infection were much higher at 13 and $20 \%$ in the nail and plate groups, respectively. This may potentially be of more serious long-term consequence in the context of internal fixation. Direct comparison with our study group is difficult given the different inclusion criteria and study design. All the FixDT patients had closed, extra-articular fractures, and patients were excluded in whom it was felt that, for any reason, internal fixation was not in their best interests. In our unit, virtually all patients not meeting these criteria are treated using llizarov frames, many of whom are included in this case series. This is our usual practice and undoubtedly introduces significant selection bias to more complex injuries in higher-risk patients being treated with llizarov frames. Nevertheless, the results of FixDT appear to show that low early rates of serious infection can be achieved in carefully selected patients with extra-articular fractures treated by internal fixation.

Unexpected reoperations were undertaken in $18 \%$ of patients in this study, comparing favorably with reported rates from the previous series. Pooled results from studies reporting outcomes in patients treated for extra-articular fractures by internal fixation revealed unplanned reintervention rates of $29-36 \%$, again with highly variable rates from 0 to $59 \%$ reported between individual studies. $^{32,35}$ Higher reoperation rates were reported in the plate fixation groups and a large number of these were metal-ware removal.

Rates of significant malunion were very low in our series. The only patient with significant coronal plane malalignment demanded frame removal before the treating surgeon advocated this and then removed their protective cast, losing position and uniting in 20 degrees of valgus. This compares very favorably with pooled analysis of studies comparing IMN and internal fixation for extra-articular injuries. ${ }^{36}$ The most recent found significant malunion rates of $20 \%$ in the nail and $10 \%$ in the plate patients. This highlights the ability of the circular frame construct to achieve and maintain alignment in peri-articular injuries. 
Patient-reported outcome measures indicate that while reasonable results can be obtained, some patients still suffer significant symptoms at medium-term follow-up. It is not surprising that severity of articular injury and OA was associated with significant impairment of ankle function and quality of life and this is consistent with previous studies. ${ }^{28,34}$ Seventy-six percent of patients with extra-articular fractures achieved O\&M scores rated excellent or good at more than 6 months post-treatment compared with only $55 \%$ of those with intra-articular injury. This difference was even more striking in those with $\mathrm{AO} 43 \mathrm{C} 3$ injuries who achieved good or excellent O\&M scores in only $35 \%$ compared with $75 \%$ for those with other injury patterns. It is perhaps of note that O\&M scores reported from the FixDT study at 12 months post-treatment are comparable to those in our series at more than 6 months post frame removal (FixDT mean of 74 vs median of 73 in our series for all patients, 80 for extra-articular fractures). ${ }^{7}$ It is not possible to draw direct comparisons as our patient's scores were collected longer after their injuries (median 401 days). However, it is important to consider that the patients in our llizarov series had significantly more severe injuries, with $63 \%$ of the injuries being intra-articular and $28 \%$ open.

Though an ongoing impact on health-related quality of life as measured by the EuroQOL is apparent, this is less striking than the ankle function scores when comparing different subgroups (Fig. 6). VASs were only slightly lower in those with $43 \mathrm{C} 3$ fractures, and there was no difference when comparing patients with $43 \mathrm{~A}$ to those with 43C type fractures. Comparison with UK norms for middle-aged adults does, however, reveal that these injuries impact reported health-related quality of life. ${ }^{37}$ Patients reporting any problems in our study group at more than 6 months post frame removal were more common across all domains (usual activities, 36 vs 15\%; anxiety and depression, 35 vs $22 \%$; mobility, 43 vs $15 \%$; pain, 60 vs $41 \%$; and self-care, 12 vs $4 \%$ ). However, more severe ratings were unusual with more than $80 \%$ of patients reporting slight or no, and less than $10 \%$ severe or extreme, problems. This demonstrates the significant impact that these injuries have on function and quality of life and this information should be shared with patients during treatment. The VAS results (median 85), were comparable to published population norms for a healthy UK adult population which ranges from 87 (in 25-34-year-olds) to 74 (in those aged 75 or more). This perhaps indicates that this score is less sensitive than considering the individual domains.

This study has limitations that must be considered when drawing conclusions. While using prospectively identified patients and partially prospectively assembled data, it is essentially a retrospective study and is therefore subject to many of the limitations associated with using this methodology. Though follow-up to frame removal is complete, many patients did not complete patient-reported outcome scores. Though we found few differences in recorded variables between those who completed outcome forms and those who did not, these results could still be subject to selection bias, as it is unclear if other patient-related factors might influence form completion. These data were also collected at a variety of times post frame removal which weakens its strength. Long-term outcome data is not available, and it is not possible to systematically examine progression to degenerative disease. We plan to undertake a long-term follow-up study for this purpose. While it is possible to compare with historic patients from other studies, this work cannot provide a direct comparison between different forms of treatment. A major flaw in pooled analysis is the variance in inclusion criteria and indeed inherent selection bias present in a tertiary referral Ilizarov service. A direct comparison between open reduction and internal fixation and external ring fixation with an assessment of clinical and functional outcome scores may be more valuable in this regard. A multicentre randomised controlled trial in closed intra-articular fractures comparing Ilizarov treatment with internal fixation has recently begun recruiting, which may help partially address this question. ${ }^{38}$

\section{Conclusion}

To our knowledge, this is the largest reported cohort of patients with distal tibial fractures treated by circular external fixation. This appears to be effective and safe. While patient-reported outcomes appear good considering injury severity, a significant proportion of patients still report functional impairment at medium-term follow-up. This information should be helpful when counselling patients regarding treatment options and expected return to normal function.

\section{References}

1. Scolaro J, Ahn J. Pilon fractures. Clin Orthop Relat Res 2011;469(2):621623. DOI: 10.1007/s11999-010-1509-z.

2. Jacob N, Amin A, Giotakis N, et al. Management of high-energy tibial pilon fractures. Strategies Trauma Limb Reconstr 2015;10(3):137-147. DOI: 10.1007/s11751-015-0231-5.

3. Joveniaux $P$, Ohl X, Harisboure A, et al. Distal tibia fractures: management and complications of 101 cases. Int Orthop 2010;34(4):583-588. DOI: 10.1007/s00264-009-0832-z.

4. Vasiliadis ES, Grivas TB, Psarakis SA, et al. Advantages of the llizarov external fixation in the management of intra-articular fractures of the distal tibia. J Orthop Surg Res 2009;4:35. DOI: 10.1186/1749-799X-4-35.

5. Harwood PJ, Fragkakis E. Circular frame treatment of distal tibial fractures. In: Practical procedures in orthopaedic trauma surgery; 2014. p. 25-372.

6. Hessmann M, Nork S, Sommer C, et al. Distal tibial fractures evidence summary; 2016. Available from: https://www2.aofoundation.org/.

7. Costa ML, Achten J, Griffin J, et al. Effect of locking plate fixation vs intramedullary nail fixation on 6-month disability among adults with displaced fracture of the distal tibia: the UK FixDT randomized clinical trial. JAMA 2017;318(18):1767-1776. DOI: 10.1001/jama.2017.16429.

8. Nanchahal J. Standards for the management of open fractures of the lower limb. London: Royal Society of Medicine Press Ltd.; 2009.

9. National Institute for Health and Care Excellence (UK). Fractures (Complex): assessment and management (NICE Guideline 37); 2016. Available from: https://www.ncbi.nlm.nih.gov/books/NBK368212/.

10. Kellam JF, Meinberg EG, Agel J, et al. Tibia: fracture and dislocation classification compendium-2018: international comprehensive classification of fractures and dislocations committee. J Orthop Trauma 2018;32(Suppl. 1):S49-S60.

11. Gustilo RB, Mendoza RM, Williams DN. Problems in the management of type III (severe) open fractures: a new classification of type III open fractures. J Trauma 1984;24(8):742-746. DOI: 10.1097/00005373198408000-00009.

12. Paley D, Tetsworth K. Mechanical axis deviation of the lower limbs. Preoperative planning of multiapical frontal plane angular and bowing deformities of the femur and tibia. Clin Orthop Relat Res 1992:65-71.

13. Ovadia DN, Beals RK. Fractures of the tibial plafond. J Bone Joint Surg Am 1986;68(4):543-551.

14. Tanaka Y, Takakura Y, Hayashi K, et al. Low tibial osteotomy for varustype osteoarthritis of the ankle. J Bone Joint Surg Br 2006;88(7):909913. DOI: 10.1302/0301-620X.88B7.17325.

15. Paley D. Problems, obstacles, and complications of limb lengthening by the Ilizarov technique. Clin Orthop Relat Res 1990:81-104.

16. Olerud C, Molander H. A scoring scale for symptom evaluation after ankle fracture. Arch Orthop Trauma Surg 1984;103(3):190-194. DOI: 10.1007/BF00435553. 
17. Lysholm J, Gillquist J. Evaluation of knee ligament surgery results with special emphasis on use of a scoring scale. Am J Sports Med 1982;10(3):150-154. DOI: 10.1177/036354658201000306.

18. Krabbe $P$, Weijnen $T$. Guidelines for analysing and reporting EQ-5D outcomes. In: Brooks R, Rabin R, de Charro F, editors. The measurement and valuation of health status using EQ-5D: a european perspective: evidence from the EuroQol BIOMED research programme. Dordrecht: Springer Netherlands; 2003. p. 7-19.

19. Taylor DM, Tebby JM, Foster PA, et al. Temporary skeletal stabilization in major trauma. Orthop Trauma 2015;29(6):359-373. DOI: 10.1016/j. mporth.2015.10.001.

20. British Orthopaedic Association. BOAST-diagnosis and management of compartment syndrome of the limbs; 2014 Available from: https://www.boa.ac.uk/resources/knowledge-hub/ boast-10-pdf.html.

21. Harwood P, Taylor DM. Segmental tibia shaft fractures - extra articular ilizarov reduction techniques. In: Giannoudis PV, editor. Fracture reduction and fixation techniques: spine-pelvis and lower extremity. Cham: Springer International Publishing; 2020. p. 351-371.

22. Timms A, Vincent M, Santy-Tomlinson J, et al. A fresh consensus for pin site care in the UK. Int J Orthop Trauma Nurs 2013;17(1):19-28 10p. DOI: 10.1016/j.ijotn.2012.04.005.

23. Petrie A. Statistics in orthopaedic papers. J Bone Joint Surg $\mathrm{Br}$ 2006;88(9):1121-1136. DOI: 10.1302/0301-620X.88B9.17896.

24. Sheffler LC, Yoo B, Bhandari M, et al. Observational studies in orthopaedic surgery: the STROBE statement as a tool for transparent reporting. J Bone Joint Surg Am 2013;95(3):e14(1-12). DOI: 10.2106/ JBJS.L.00484.

25. Meng YC, Zhou XH. External fixation versus open reduction and internal fixation for tibial pilon fractures: A meta-analysis based on observational studies. Chin J Traumatol 2016;19(5):278-282. DOI: 10.1016/j.cjtee.2016.06.002.

26. Zhang SB, Zhang YB, Wang SH, et al. Clinical efficacy and safety of limited internal fixation combined with external fixation for Pilon fracture: a systematic review and meta-analysis. Chin J Traumatol 2017;20(2):94-98. DOI: 10.1016/j.cjtee.2016.06.012.

27. Danoff JR, Saifi C, Goodspeed DC, et al. Outcome of 28 open pilon fractures with injury severity-based fixation. Eur J Orthop Surg Traumatol 2015;25(3):569-575. DOI: 10.1007/s00590-014-1552-7.
28. Galante VN, Vicenti G, Corina G, et al. Hybrid external fixation in the treatment of tibial pilon fractures: a retrospective analysis of 162 fractures. Injury 2016;47(Suppl. 4):S131-S137. DOI: 10.1016/j. injury.2016.07.045.

29. Younis $M$, Aldahamsheh $O$, Thalib $L$, et al. External fixation versus open reduction and internal fixation of pilon fractures: a systematic review and meta-analysis. J Musculoskelet Surg Res 2018;2(2):41-50. DOI: 10.4103/jmsr.jmsr_38_17.

30. Yu J, Li L, Wang T, et al. Intramedullary nail versus plate treatments for distal tibial fractures: a meta-analysis. Int J Surg 2015;16:60-68. DOI: 10.1016/j.ijsu.2015.02.004.

31. Kwok CS, Crossman PT, Loizou CL. Plate versus nail for distal tibial fractures: a systematic review and meta-analysis. J Orthop Trauma 2014;28(9):542-548. DOI: 10.1097/BOT.0000000000000068.

32. Xue $\mathrm{XH}$, Yan SG, Cai XZ, et al. Intramedullary nailing versus plating for extra-articular distal tibial metaphyseal fracture: a systematic review and meta-analysis. Injury 2014;45(4):667-676. DOI: 10.1016/j. injury.2013.10.024.

33. Calori GM, Tagliabue L, Mazza E, et al. Tibial pilon fractures: which method of treatment? Injury 2010;41(11):1183-1190. DOI: 10.1016/j. injury.2010.08.041.

34. Leung F, Kwok HY, Pun TS, et al. Limited open reduction and llizarov external fixation in the treatment of distal tibial fractures. Injury 2004;35(3):278-283. DOI: 10.1016/s0020-1383(03)00172-4.

35. Sun $M$, Zhang $B$, He B, et al. Comparison of intramedullary nailing and plate fixation in treatment of distal extra-articular tibial fractures: a systematic review and meta-analysis. Int J Clin Exp Med 2017;10(7):11157-11164.

36. Balogi Z, Multhoff G, Jensen TK, et al. Hsp70 interactions with membrane lipids regulate cellular functions in health and disease. Prog Lipid Res 2019;74:18-30. DOI: 10.1016/j.plipres.2019.01.004.

37. Janssen B, Szende A. Population norms for the EQ-5D. In: Szende A, Janssen B, Cabases J, editors. Self-reported population health: an international perspective based on EQ-5D. Dordrecht: Springer Netherlands; 2014. p. 19-30.

38. Northgraves $M$, Sharma H. External frame versus internal locking plate for articular pilon fracture fixation. NIHR; 2018. Available from: https://ukctg.nihr.ac.uk/trials/trial-details/trialdetails?trialNumber =ISRCTN98152560. 